\title{
CNS Stimulant Drug Measurement
}

National Cancer Institute

\section{Source}

National Cancer Institute. CNS Stimulant Drug Measurement. NCI Thesaurus. Code C75342.

The determination of the amount of any drug that stimulates the central nervous system (CNS) present in a sample. 